\title{
Adaptive Projective Lag Synchronization of T and Lu Chaotic Systems
}

\author{
Hamed Tirandaz ${ }^{1}$, Mohsen Ahmadnia ${ }^{2}$, Hamidreza Tavakoli ${ }^{3}$ \\ Electrical and Computer Engineering, Hakim Sabzevari University, Sabzevar, Iran
}

\begin{tabular}{|c|c|}
\hline Article Info & ABSTRACT \\
\hline Article history: & In this paper, the synchronization problem of $\mathrm{T}$ chaotic system and $\mathrm{Lu}$ \\
\hline Received Jan 5, 2017 & $\begin{array}{l}\text { chaotic system is studied. The parameter of the drive } \mathrm{T} \text { chaotic system is } \\
\text { considered unknown. An adaptive projective lag control method and also }\end{array}$ \\
\hline Revised Jun 25, 2017 & parameter estimation law are designed to achieve chaos synchronization \\
\hline Accepted Jul 10, 2017 & $\begin{array}{l}\text { problem between two chaotic systems. Then Lyapunov stability theorem is } \\
\text { utilized to prove the validity of the proposed control method. After that, }\end{array}$ \\
\hline Keyword: & $\begin{array}{l}\text { some numerical simulations are performed to assess the performance of the } \\
\text { proposed method. The results show high accuracy of the proposed method in }\end{array}$ \\
\hline Adaptive method & \\
\hline
\end{tabular}

Lyapunov stability theorem

Chaos synchronization

Projective lag method

Copyright () 2017 Institute of Advanced Engineering and Science. All rights reserved.

\section{Corresponding Author:}

Hamed Tirandaz,

Electrical and Computer Engineering Department,

Hakim Sabzevari University,

Sabzevar, Iran.

Email: tirandaz@hsu.ac.ir

\section{INTRODUCTION}

Sensitivity to the initial values of the state variables is the main feature of any chaotic system, which causes exponentially different motion trajectories of the state variables with different initial conditions. The problem of chaos synchronization has received a lot of attention in the last three decades due to its potential applications in many different fields such as: physics, chemistry, electrical engineering, economics and secure communications. Until now, many kind of chaos control and synchronization schemes have developed by the researchers. Active method [1]-[3], adaptive method [4]-[6], phase method [7], backstepping method [8],[9], lag method [10], impulsive method [11],[12], linear feedback method [13],[14], nonlinear feedback control [15],[16], and projective method [17]-[20] are some of the investigated method during the last recent years. Among these investigated methods, chaos synchronization related to the projective method has considerably noticed during the last few decades due to its proportional feature, which the response chaotic system can be synchronized up to a typical aligned scaling factors. So far many types of projective methods have been studied by the researchers. Modified projective synchronization (MPS) [21]-[24], function projective synchronization (FPS) [25],[26], modified function projective synchronization (MFPS) [27], generalized function projective synchronization [28]-[30] are some of the projective related method for control and synchronization between two identical/non-identical chaotic systems. But, projective lag hybrid synchronization is rarely investigated by the researchers. So, this paper is devoted to the synchronization problem between $\mathrm{T}$ chaotic system and Lorenz chaotic system by designing an appropriate adaptive hybrid projective lag synchronization method.

The rest reminder of this paper is constructed as follows: In Section 2, the structure of the T chaotic system and Lorenz chaotic system are described. Then, in Section 3, the problem of chaos synchronization of $\mathrm{T}$ chaotic system and Lorenz chaotic system is given. An adaptive projective lag control method is designed 
to achieve the chaos synchronization problem between two chaotic systems. Then, the validity of the proposed method is verified by means of Lyapunov stability theorem and adaptive control theory. In Section 3 , some numerical simulations are presented to show the effectiveness of the theorical discussions in the previous section. Finally, some numerical results are given in Section 5.

\section{PRELIMINARIES}

In this section, the structure of the $\mathrm{T}$ chaotic system and the Lorenz chaotic system are given. In addition, their chaotic behavior are studied. Recently, a new chaotic system, as $\mathrm{T}$ chaotic system is introduced in [31], which can be described by means of three dynamical equations with three state variables as follows:

$$
\begin{aligned}
& \dot{x}_{1}=a\left(x_{2}-x_{1}\right) \\
& \dot{x}_{2}=(b-a) x_{1}-a x_{1} x_{3} \\
& \dot{x}_{3}=x_{1} x_{2}-c x_{3}
\end{aligned}
$$

where $x_{1}, x_{2}$ and $x_{3}$ are the state variables of the system and $a, b$ and $c$ are the three state variables of the T system. When $a=2.1, b=30$ and $c=0.6$, the behavior of the T system (1) is chaotic. The phase portraits of the $\mathrm{T}$ chaotic system with these system parameters and the initial state variables $x_{1}=4.3, x_{2}=7.2$ and $x_{3}=5.8$ is shown in Figure 1. In addition, Lorenz chaotic system can be given as follows:

$$
\begin{aligned}
& \dot{y}_{1}=-\alpha y_{1}+\alpha y_{2} \\
& \dot{y}_{2}=\beta y_{1}-y_{2}-y_{1} y_{3} \\
& \dot{y}_{3}=y_{1} y_{2}-\gamma y_{3}
\end{aligned}
$$

where $x_{1}, x_{2}$ and $x_{3}$ are the state variables of the Lorenz chaotic systems. The chaotic behavior of the Lorenz system (2) is illustrated in Figure 2, with system parameters and initial state variables as: $x_{1}=11, x_{2}=7$ and $x_{3}=9$.

\section{SYNCHRONIZATION}

Assume the $\mathrm{T}$ chaotic system presented in (1), as the drive system then response system can be given based on the Lorenz chaotic system (2) as follows:

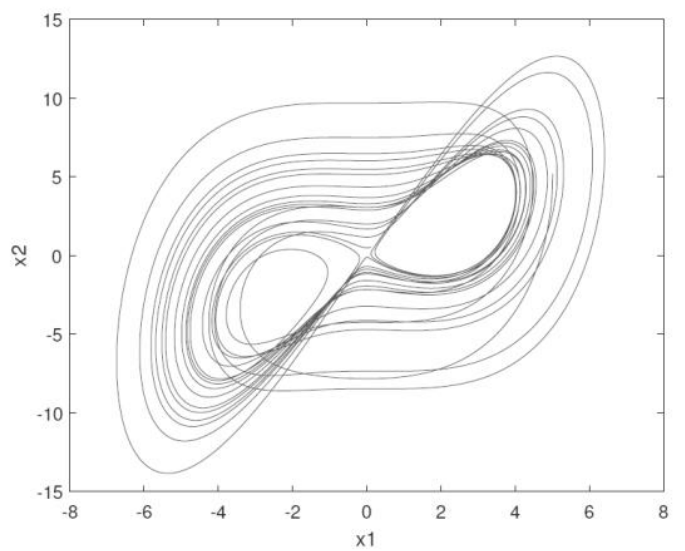

(a)

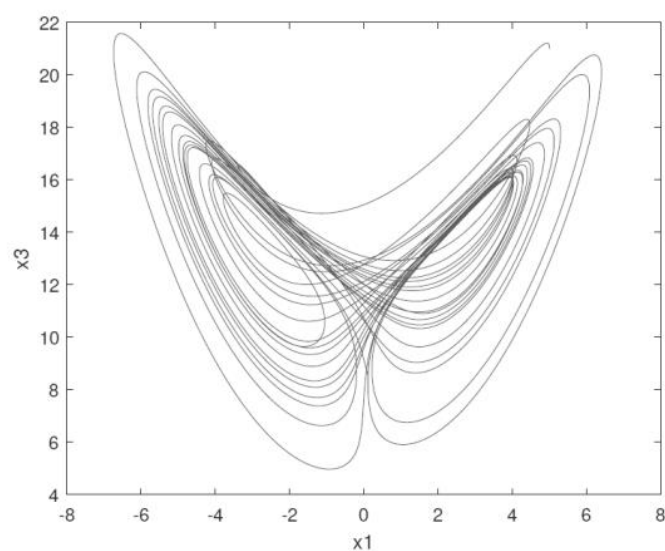

(b) 


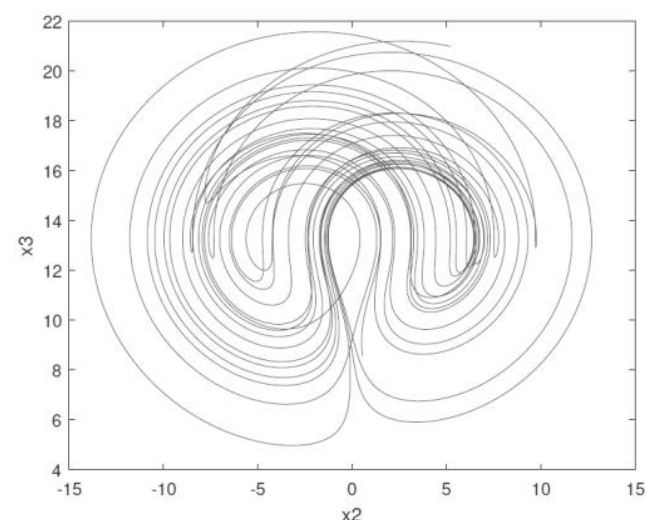

(c)

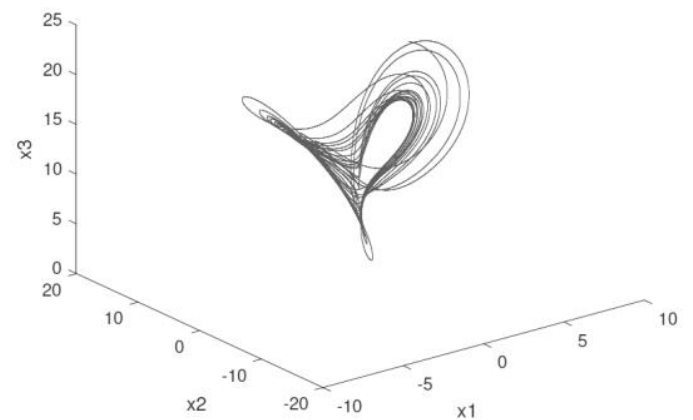

(d)

Figure 1. Time portrait of the T chaotic system

$$
\begin{aligned}
& \dot{y}_{1}=-(a+\Delta a) y_{1}+(a+\Delta a) y_{2}+u_{1} \\
& \dot{y}_{2}=(b+\Delta b) y_{1}-y_{2}-y_{1} y_{3}+u_{2} \\
& \dot{y}_{3}=y_{1} y_{2}-(c+\Delta c) y_{3}+u_{3}
\end{aligned}
$$

where $a, b$ and $c$ are the parameters of the drive $\mathrm{T}$ chaotic system (1), and $\Delta a, \Delta b$ and $\Delta c$ represent the disparity amount of system parameters. $u_{1}, u_{2}$ and $u_{3}$ are the feedback controller, which have to be designed in such way that response state variables of Lorenz chaotic system (3) track the trajectories of the drive $\mathrm{T}$ chaotic system (1), asymptotically.

Then the synchronization errors between the state variables of the $\mathrm{T}$ chaotic system (1) and the Lorenz chaotic system (3) can be obtain based on the projective lag synchronization errors as follows:

$$
\begin{aligned}
& e_{1}=y_{1}-\delta_{1} x_{1}(t-\tau) \\
& e_{2}=y_{2}-\delta_{2} x_{2}(t-\tau) \\
& e_{3}=y_{3}-\delta_{3} x_{3}(t-\tau)
\end{aligned}
$$

where $\delta_{1}, \delta_{2}$ and $\delta_{3}$ are the three modified projective scaling error factor and $\tau$ states the time-delay of the system. The dynamical representation of system errors can be described based on the synchronization errors (4) as follows:

$$
\begin{aligned}
& \dot{e}_{1}=\dot{y}_{1}-\delta_{1} \dot{x}_{1}(t-\tau) \\
& \dot{e}_{2}=\dot{y}_{2}-\delta_{2} \dot{x}_{2}(t-\tau) \\
& \dot{e}_{3}=\dot{y}_{3}-\delta_{3} \dot{x}_{3}(t-\tau)
\end{aligned}
$$

In the following the concept of chaos synchronization between two chaotic systems is given with a definition. 


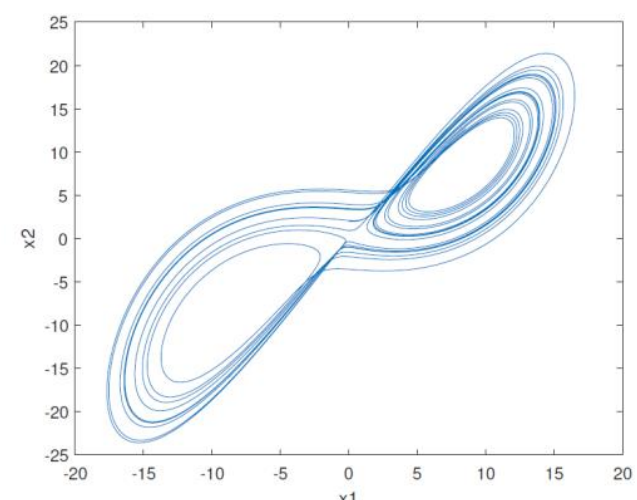

(a)

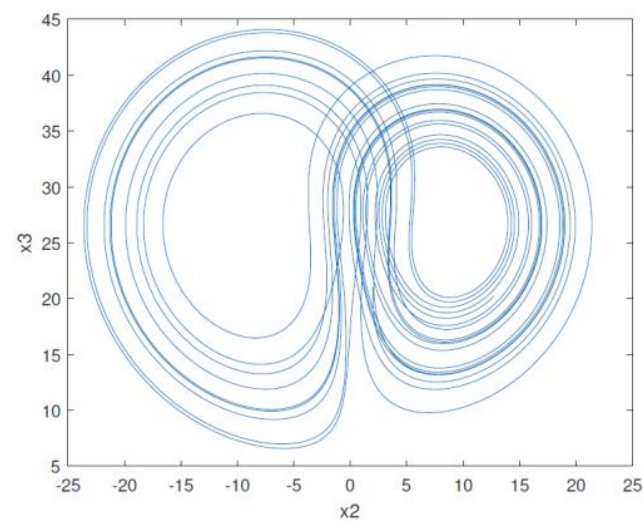

(c)

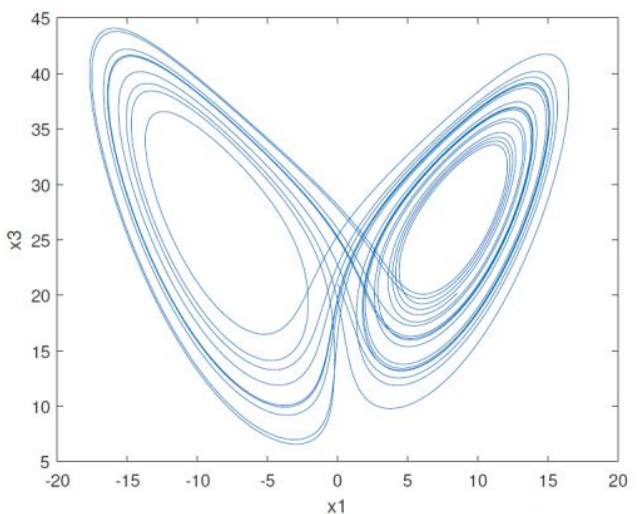

(b)

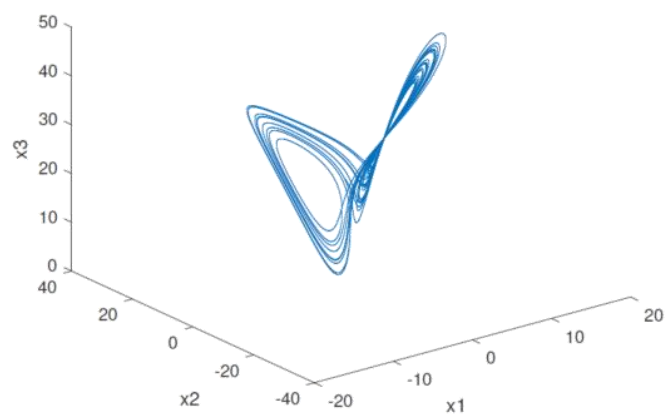

(d)

Figure 2. Time portrait of the Lorenz chaotic system

Definition 1. The trivial solution of the system error (4) is said to be stable if for any projective scaling factor $\delta_{1}, \delta_{2}$ and $\delta_{3}$ and any time-delay $\tau$ with any initial state variables $x_{1}, x_{2}$ and $x_{3}$ and $y_{1}, y_{2}$ and $y_{3}$ and for any $\epsilon>0$, there exist a $N>0$ such that for any time $t>N$, we have $\left|e_{i}\right|<\epsilon$. In other words, $\lim _{t \rightarrow \infty}\left|e_{i}\right|=0$ for all $i=1,2,3$. In the following theorem, an appropriate feedback control law and a parameter estimation law are given to achieve drive-response synchronization and to force the trivial solution of the system error (4) to be stable.

Theorem 1. The drive T chaotic system (1) and the response Lorenz chaotic system (3) would be synchronized and also synchronization errors defined in (4) would be stable, if the control law and parameter estimation law are taken as follows:

$$
\begin{aligned}
& u_{1}=(a+\Delta a)\left(y_{1}-y_{2}\right)+\delta_{1}(a+\Delta a)\left(x_{2}(t-\tau)-x_{1}(t-\tau)\right)-k_{1} e_{1} \\
& u_{2}=-(b+\Delta b) y_{1}+y_{2}+y_{1} y_{3}+\delta_{2}\left[\begin{array}{c}
((b+\Delta b)-(a+\Delta a)) x_{1}(t-\tau) \\
-(a+\Delta a) x_{1}(t-\tau) x_{3}(t-\tau)
\end{array}\right]-k_{2} e_{2} \\
& u_{3}=-y_{1} y_{2}+(c+\Delta c) y_{3}-k_{3} e_{3}+\delta_{3}\left[x_{1}(t-\tau) x_{2}(t-\tau)-(c+\Delta c) x_{3}(t-\tau)\right]
\end{aligned}
$$

and,

$$
\begin{aligned}
\dot{\Delta a} & =\delta_{1}\left(x_{2}-x_{1}\right)-\delta_{2} x_{1} e_{2}-\delta_{2} e_{2} x_{1}(t-\tau) x_{3}(t-\tau) \\
\dot{\Delta b} & =\delta_{2} x_{1}(t-\tau) e_{2} \\
\dot{\Delta c} & =-\delta_{3} x_{3}(t-\tau) e_{3}
\end{aligned}
$$

Where $k_{1}, k_{2}, k_{3}, \varphi_{1}, \varphi_{2}$ and $\varphi_{3}$ are the constant positive values.

Proof. Let the Lyapunov stability function as follows: 


$$
V=\frac{1}{2}\left(e_{1}^{2}+e_{2}^{2}+e_{3}^{2}+(\Delta a)^{2}+(\Delta b)^{2}+(\Delta c)^{2}\right)
$$

It is clear that $\mathrm{V}$ is positive definite. Then, the derivative of $\mathrm{V}$ along the time domain would be:

$$
\dot{V}=\frac{1}{2}\left(e_{1} \dot{e}_{1}+e_{2} \dot{e}_{2}+e_{3} \dot{e}_{3}+(\Delta a)(\Delta a)^{\prime}+(\Delta b)(\Delta b)^{\prime}+(\Delta c)(\Delta c)^{\prime}\right)
$$

With considering the dynamical errors in (5) and dynamical of parameter estimation errors in (7), and subsequently, dynamical representation of drive system (1) and response system (2) and adaptive projective lag feedback controller proposed in (6), the derivative of Lyapunov function (9) can be simplified as follows:

$$
\dot{V}=-k_{1} e_{1}^{2}-k_{2} e_{2}^{2}-k_{3} e_{3}^{2}-\varphi_{1}(\Delta a)^{2}-\varphi_{2}(\Delta b)^{2}-\varphi_{3}(\Delta c)^{2}
$$

Since the Lyapunov candidate function (8) is positive definite and its derivative is negative definite. Then, the stability of the proposed control law 6) and parameter estimation law (7) is proved. Thus, the anticipated synchronization between the state variables of the drive $\mathrm{T}$ chaotic system (1) and the response chaotic system (3) would be achieved. Furthermore, the synchronization errors defined in (4) are stabilized.

\section{NUMERICAL SIMULATIONS}

In this section, some numerical results related to the synchronization of the drive $\mathrm{T}$ chaotic system (1) and the response Lorenz chaotic system (3) are given. During this section, the unknown parameters of the drive $\mathrm{T}$ chaotic system (1) are considered as $a=2, b=2.3$ and $c=1.5$. Furthermore, the initial estimation of parameters are set as $\Delta a=0.3, \Delta b=0.5$ and $\Delta c=0.2$. The initial state variables of the drive $\mathrm{T}$ chaotic system (1) are selected as: $x_{1}=12, x_{2}=9$ and $x_{3}=11$ and also the response Lorenz chaotic system (3) are chosen as $y_{1}=2, y_{2}=1.5$ and $y_{3}=3$.

The effectiveness of the proposed control law for synchronization of the drive T chaotic system (1) and the follower Lorenz chaotic system (3) with unknown drive system parameters $\mathrm{a}, \mathrm{b}$, and $\mathrm{c}$ is shown in Figure 3, 4 and 5 for different projective synchronization factors $\Lambda=\left(\lambda_{1}, \lambda_{2}, \lambda_{3}\right)$ as follows:

$$
\begin{aligned}
\Lambda_{1} & =\operatorname{diag}(1,1,1) \\
\Lambda_{2} & =\operatorname{diag}(-1,-1,-1) \\
\Lambda_{3} & =\operatorname{diag}(1.02,0.997,1.012)
\end{aligned}
$$

Figure $3 \mathrm{a}$ shows the projectvie lag synchronization between the state variabel of the drive $\mathrm{T}$ chaotic system and response Lorenz chaotic system with considering time-delay as: $\tau=0$. The estimation errors of system parameters for this projective scaling $\Lambda_{1}$ (complete synchronization) with $\tau=0$ is given in Figure $1 \mathrm{~b}$. In addition, projective lag synchronization and disparity amount of parameter estimation with scaling factor $\Lambda_{1}$ and assuming the time-delays as $\tau=0.5$ are shown in Figure $3 \mathrm{c}$ and Figure $3 \mathrm{~d}$, respectively.

Anti-synchronization problem is illustrated in Figure 4, with projective scaling $\Lambda_{2}=\operatorname{diag}(-1,-1,-1)$. Figure $4 \mathrm{a}$ and $4 \mathrm{~b}$ show the anti-synchronization problem without considerening any time-delays. While Figure $4 \mathrm{c}$ and $4 \mathrm{~d}$ depict the anti-synchronization problem with considering timedelay as as $\tau=0.5$.

Finally, another projective synchronization is depicted in Figure 5, with a typical scaling factors $\Lambda_{3}=\operatorname{diag}(1.02,0.997,1.012)$. Figure $5 \mathrm{a}$ and $5 \mathrm{~b}$ show the projective lag synchronization problem and disparity of parmaeter estimation between the drive chaotic system (1) and response chaotic system (2) with a typical projective scaling $\Lambda_{3}$ and without considering any time-delays $(\tau=0)$. In similar manner, the projecitve lag synchronization and disparitiy amount of parameter estimations are achived with projective scaling $\Lambda_{3}$ and assuming the system time-delay as $\tau=0.5$ in Figures $5 \mathrm{c}$ and $5 \mathrm{~d}$, respecitvely. As it can be seen from these results, the anticipated synchronizations are achived. Furthermore, the disparity amount of system parameters estimations converge to zero, with all projective scaling factors $\Lambda_{1}, \Lambda_{2}$ and $\Lambda_{3}$. 


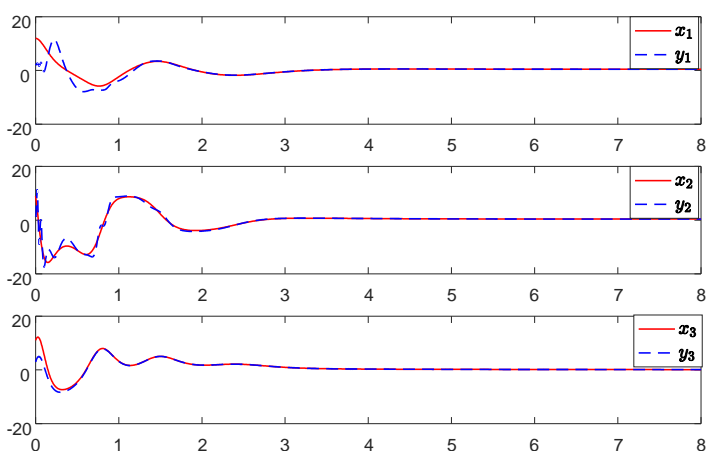

(a) synchronization error with $(\tau=0)$
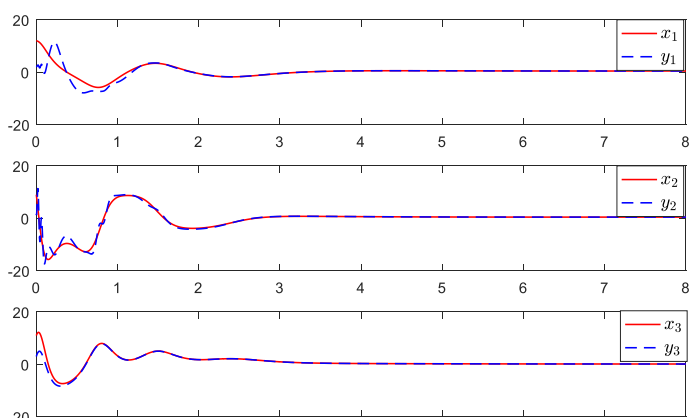

(c) synchronization error with $(\tau=0.5)$

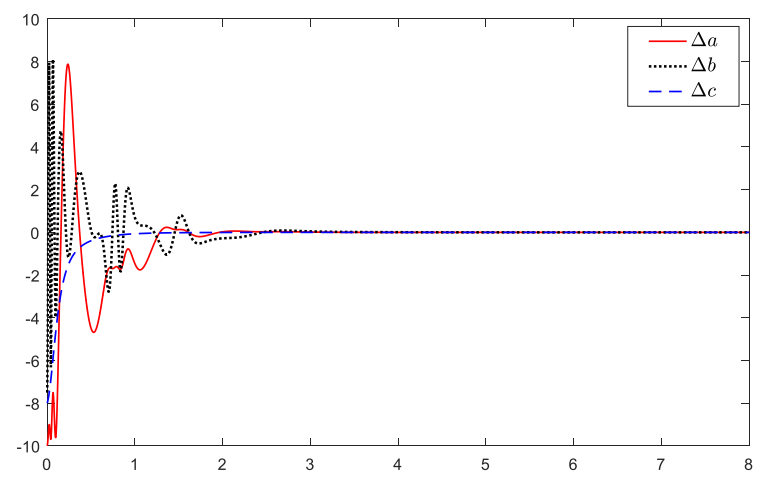

(b) Parameter estimation error with $(\tau=0)$

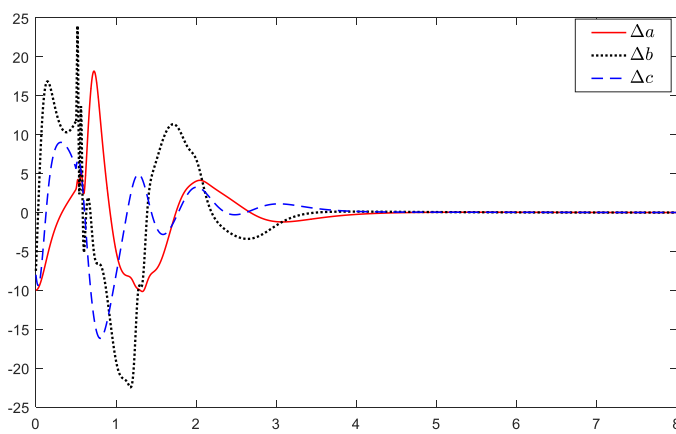

(d) Parameter estimation error with $(\tau=0.5)$

Figure 3. projective lag synchronization of T chaotic system (1) and Lorenz chaotic system (3) with projective scaling factor $\Lambda=(1,1,1)$
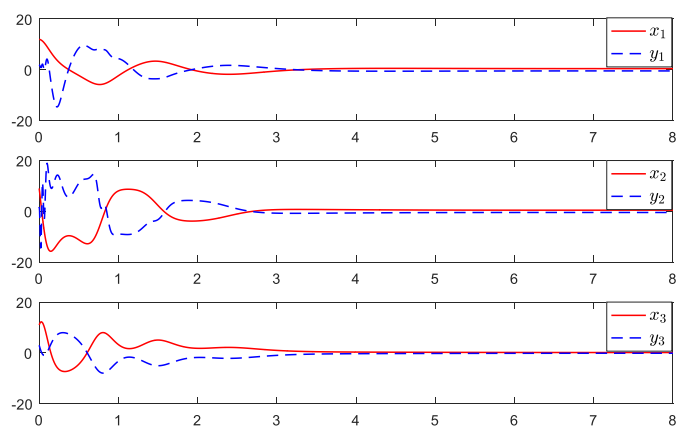

(a) synchronization error with $(\tau=0)$

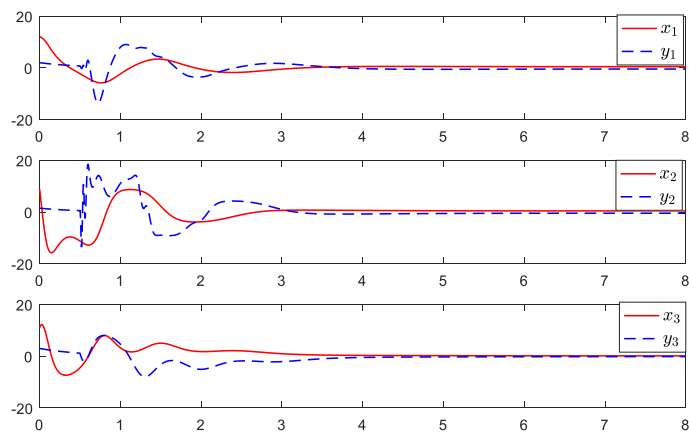

(c) synchronization error with $(\tau=0.5)$

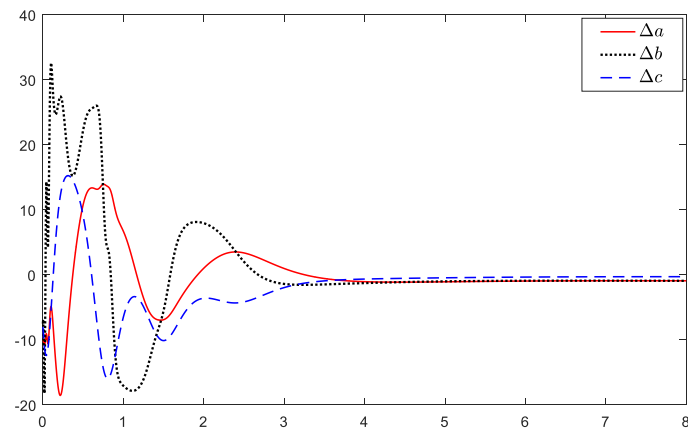

(b) Parameter estimation error with $(\tau=0)$

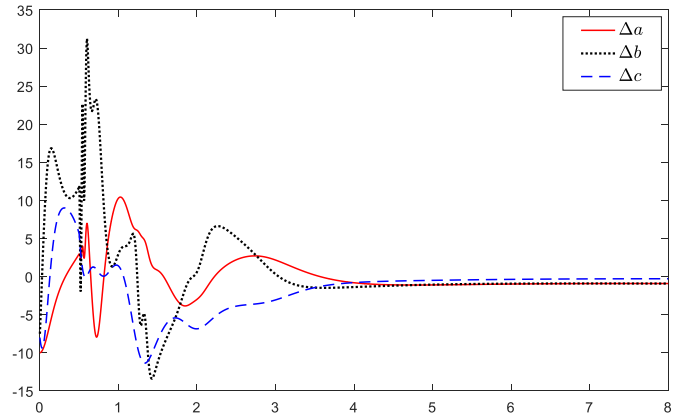

(d) Parameter estimation error with $(\tau=0.5)$

Figure 4. projective lag synchronization of T chaotic system (1) and Lorenz chaotic system (3) with projective scaling factor $\Lambda=(-1,-1,-1)$ 

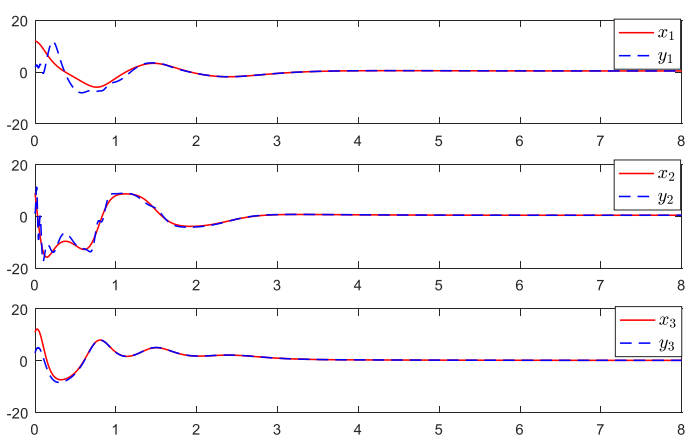

(a) synchronization error with $(\tau=0)$
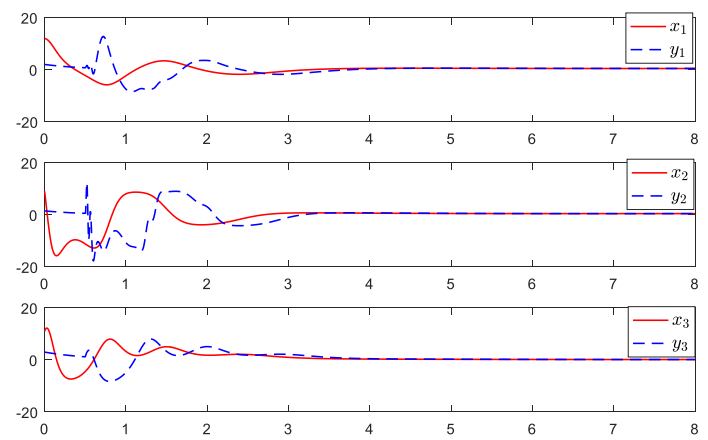

(c)synchronization error with $(\tau=0)$

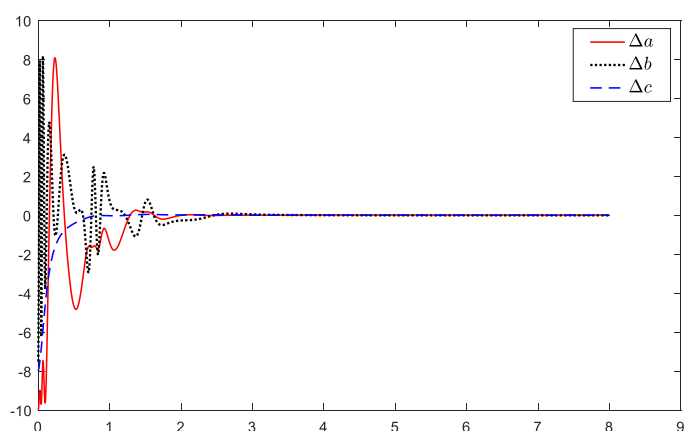

(b) Parameter estimation error with $(\tau=0)$

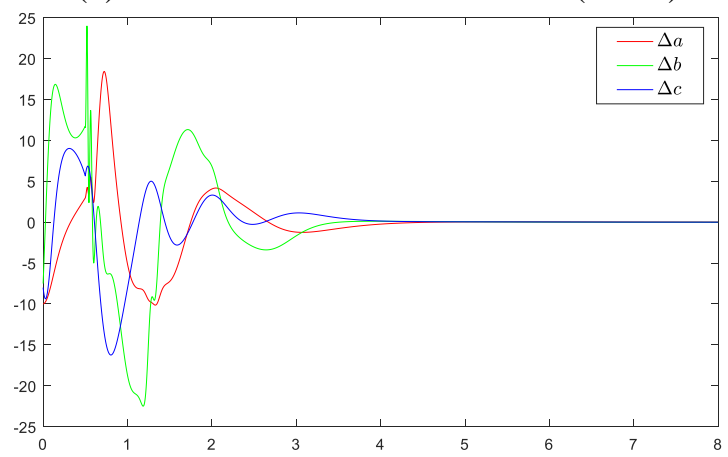

(d)Parameter estimation error with $(\tau=0)$

Figure 5. projective lag synchronization of $\mathrm{T}$ chaotic system (1) and Lorenz chaotic system (3) with projective scaling factor $\Lambda=(1.02,0.997,1.012)$

\section{CONCLUSIONS}

In this study, a new adaptive projective lag control method for synchronization of $\mathrm{T}$ chaotic system as the drive system and the Lorenz chaotic system as the response system is achieved. The parameters of the drive chaotic system are considered unknown. Thus, adaptive control is utilized to achieve the synchronization. Projective control method is given based on a Lyapunov candidate function to force the state variables of the response Lorenz chaotic system to follow the motion trajectories of the drive $\mathrm{T}$ chaotic system. Furthermore, some numerical simulations are performed to validate the effectiveness of the proposed projective lag synchronization method. The results show that the anticipated drive- response synchronization is derived and also the disparity amount of parameter estimations converge to zero as time goes to the infinity.

\section{REFERENCES}

[1] H. N. Agiza and M. T. Yassen, "Synchronization of Rossler and Chen chaotic dynamical systems using active control," Physics Letters A, vol/issue: 278(4), pp. 191-197, 2001.

[2] M. T. Yassen, "Chaos synchronization between two different chaotic systems using active control," Chaos, Solitons \& Fractals, vol/issue: 23(1), pp. 131-140, 2005.

[3] S. Bhalekar and V. D. Gejji, "Synchronization of different fractional order chaotic systems using active control," Communications in Nonlinear Science and Numerical Simulation, vol/issue: 15(11), pp. 3536-3546, 2010.

[4] S. Chen and J. Lü, "Synchronization of an uncertain unified chaotic system via adaptive control," Chaos, Solitons \& Fractals, vol/issue: 14(4), pp. 643-647, 2002.

[5] T. L. Liao and S. H. Tsai, "Adaptive synchronization of chaotic systems and its application to secure communications," Chaos, Solitons \& Fractals, vol/issue: 11(9), pp. 1387-1396, 2000.

[6] S. Vaidyanathan, et al., "Backstepping Control Design for the Adaptive Stabilization and Synchronization of the Pandey Jerk Chaotic System with Unknown Parameters," International Journal of Control Theory and Applications, vol/issue: 9(1), pp. 299-319, 2016.

[7] M. C. Ho, et al., "Phase and anti-phase synchronization of two chaotic systems by using active control," Physics letters A, vol/issue: 296(1), pp. 43-48, 2002.

[8] J. H. Park, "Synchronization of Genesio chaotic system via backstepping approach," Chaos, Solitons \& Fractals, vol/issue: 27(5), pp. 1369-1375, 2006. 
[9] Y. Yu and S. Zhang, "Adaptive backstepping synchronization of uncertain chaotic system," Chaos, Solitons \& Fractals, vol/issue: 21(3), pp. 643-649, 2004.

[10] C. Li, et al., "Lag synchronization of hyperchaos with application to secure communications," Chaos, Solitons \& Fractals, vol/issue: 23(1), pp. 183-193, 2005.

[11] B. Liu, et al., "Robust impulsive synchronization of uncertain dynamical networks," IEEE Transactions on Circuits and Systems I: Regular Papers, vol/issue: 52(7), pp. 1431-1441, 2005.

[12] H. Zhang, et al., "Robust global exponential synchronization of uncertain chaotic delayed neural networks via dualstage impulsive control," IEEE Transactions on Systems, Man, and Cybernetics, Part B (Cybernetics), vol/issue: 40(3), pp. 831-844, 2010.

[13] M. Rafikov and J. M. Balthazar, "On control and synchronization in chaotic and hyperchaotic systems via linear feedback control," Communications in Nonlinear Science and Numerical Simulation, vol/issue: 13(7), pp. 1246$1255,2008$.

[14] J. Zhao and J. A. Lu, "Using sampled-data feedback control and linear feedback synchronization in a new hyperchaotic system," Chaos, Solitons \& Fractals, vol/issue: 35(2), pp. 376-382, 2008

[15] H. H. Chen, et al., "Chaos synchronization between two different chaotic systems via nonlinear feedback control," Nonlinear Analysis: Theory, Methods \& Applications, vol/issue: 70(12), pp. 4393-4401, 2009.

[16] L. Ling, et al., "Synchronization between two different chaotic systems with nonlinear feedback control," Chinese Physics, vol/issue: 16(6), pp. 1603, 2007.

[17] R. Mainieri and J. Rehacek, "Projective synchronization in three-dimensional chaotic systems," Physical Review Letters, vol/issue: 82(15), pp. 3042, 1999.

[18] D. Xu, "Control of projective synchronization in chaotic systems," Physical review E, vol/issue: 63(2), pp. 027201, 2001.

[19] G. H. Li, "Modified projective synchronization of chaotic system," Chaos, Solitons \& Fractals, vol/issue: 32(5), pp. 1786-1790, 2007

[20] D. Xu and Z. Li, "Controlled projective synchronization in nonpartially-linear chaotic systems," International Journal of Bifurcation and Chaos, vol/issue: 12(06), pp. 1395-1402, 2002.

[21] N. Cai, et al., "Modified projective synchronization of chaotic systems with disturbances via active sliding mode control," Communications in Nonlinear Science and Numerical Simulation, vol/issue: 15(6), pp. 1613-1620, 2010.

[22] X. Wang, et al., "Modified projective synchronization of fractional-order chaotic systems via active sliding mode control," Nonlinear Dynamics, vol/issue: 69(1), pp. 511-517, 2012.

[23] J. H. Park, "Adaptive modified projective synchronization of a unified chaotic system with an uncertain parameter," Chaos, Solitons \& Fractals, vol/issue: 34(5), pp. 1552-1559, 2007.

[24] H. Du, et al., "Function projective synchronization in coupled chaotic systems," Nonlinear Analysis: Real World Applications, vol/issue: 11(2), pp. 705-712, 2010.

[25] Y. Chen and X. Li, "Function projective synchronization between two identical chaotic systems," International Journal of Modern Physics C, vol/issue: 18(05), pp. 883-888, 2007.

[26] P. Zhou and W. Zhu, "Function projective synchronization for fractional-order chaotic systems," Nonlinear Analysis: Real World Applications, vol/issue: 12(2), pp. 811-816, 2011

[27] H. Du, et al., "Modified function projective synchronization of chaotic system," Chaos, Solitons \& Fractals, vol/issue: 42(4), pp. 2399-2404, 2009.

[28] S. Vaidyanathan and S. Pakiriswamy, "Generalized projective synchronization of six-term Sundarapandian chaotic systems by adaptive control," Int J Control Theory Appl, vol/issue: 6(2), pp. 153-163, 2013.

[29] G. H. Li, "Generalized projective synchronization of two chaotic systems by using active control," Chaos, Solitons \& Fractals, vol/issue: 30(1), pp. 77-82, 2006.

[30] P. Sarasu and V. Sundarapandian, "Generalized projective synchronization of two-scroll systems via adaptive control," Int J Soft Comput, vol/issue: 7(4), pp. 146-156, 2012.

[31] G. Tigan and D. Opriş, "Analysis of a 3D chaotic system," Chaos, Solitons \& Fractals, vol/issue: 36(5), pp. 1315$1319,2008$. 